\title{
STRATEGI KESANTUNAN BERBAHASA DALAM TALK SHOW $Q \& A$ DAN RELEVANSINYA TERHADAP PEMBELAJARAN BAHASA INDONESIA TINGKAT SMP
}

\author{
Tri Indrayanti \\ (Dosen Pendidikan Bahasa dan Sastra Indonesia, Fakultas Keguruan dan Ilmu \\ Pendidikan, Universitas PGRI Adi Buana Surabaya) \\ indrayanti.trie18@unipasby.ac.id
}

\begin{abstract}
The purpose of this study to describe the politeness strategies of Brown and Levinson in the $Q \& A$ talk show and describe the relevance of politeness-language strategies towards learning Indonesian at the Middle School level. The theory used to solve the problem in this study is the theory of Brown and Levinson. While the approach used is descriptive qualitative approach with data collection techniques namely documentation techniques. The results of this study indicate that the forms of Brown and Levinson's politeness strategy that occurred in the $Q$ \& A talk show in August 2018 consisted of Brown and Levinson's first politeness strategy, namely without strategies found that included speech without strategy. The second strategy of brown politeness and Levinson's positive politeness strategy is found to pay attention to the opponent's speech, exaggerate attention, agreement, and sympathy, intensify the opponent's attention by dramatizing facts, intensify using group identity markers, request approval with general topics or repeat part or all, avoiding disagreement by pretending to agree, using jokes, expressing understanding of the wishes of speakers, giving offers or promises, showing optimism, involving speakers in activities, giving questions asking for approval, giving gifts. Where negative politeness strategies are found to be pessimistic, minimize coercion, and apologize. Finally, the Off Record strategy was found which was included in the strategy. The relevance of the results of the study can be applied in learning Indonesian in junior high school class IX 3.94.10.
\end{abstract}

Keywords: Strategy, modesty, relevance of learning

\section{PENDAHULUAN}

Bahasa merupakan sistem lambang bunyi yang bersifat arbitrer artinya mana suka. Bahasa tidak bisa lepas dari kehidupan manusia karena dengan bahasa manusia bisa berkomunikasi. Sebagai alat komunikasi untuk berinteraksi, bahasa dapat dikaji secara internal maupun eksternal. Kajian secara internal dilakukan terhadap struktur bahasa seperti fonologi, morfologi, semantik, dan sintaksis. Kajian secara internal hanya menggunakan teori dan prosedur disiplin linguistik, sedangkan kajian secara eksternal melibatkan dua disiplin ilmu atau lebih yang tidak hanya menggunakan teori dan prosedur, tetapi juga menggunakan disiplin lain, misalnya sosiologi, psikologi, dan antropologi. (Chaer, 2009:1).

Pragmatik adalah cabang ilmu linguistik yang membahas tentang struktur bahasa sebagai alat komunikasi antara penutur dan pendengar, sebagai acuan pada kajian penggunaan bahasa yang berdasarkan 
konteks (Verhaar, 2012:14). Bidang kajian yang berhubungan dengan penggunaan bahasa pada konteks antara lain deiksis, praanggapan, tindak tutur, dan implikatur. Menurut Chaer, 2010:14 Implikatur adalah maksud yang terkandung di dalam suatu ujaran tetapi tidak dinyatakan secara langsung. Implikatur dibagi menjadi dua macam, yaitu implikatur konvensional dan nonkonvensional (implikatur percakapan). Implikatur konvensional tidak memperhatikan konteks, sedangkan dalam implikatur nonkonvensional, diimplikasikan tergantung pada konteks tuturan. Implikatur nonkonvensional dibagi menjadi dua yaitu prinsip kerjasama dan prinsip kesantunan.

Kesantunan merupakan hubungan antara penutur dan mitra tutur saat berkomunikasi. Kesantunan dinilai dari tata cara bicara dan gestur tubuh. Hal ini juga berkaitan dengan aturan perilaku dan etika seseorang dalam berkomunikasi sehari-hari harus dipatuhi karena telah menjadi suatu aturan yang disepakati oleh masyarakat.

Kesantunan

berbahasa

merupakan bagian yang tidak dapat dipisahkan dalam berkomunikasi karena menjadi salah satu faktor penentu keberhasilan dalam menyampaikan pesan kepada mitra tutur.

Kesantunan berbahasa peserta didik juga sangat minim sekali, bahkan ketika berbicara dengan pendidik mereka mengeluarkan katakata tidak pantas dan kurang sopan. Seharusnya hal seperti ini bisa ditindak lanjuti oleh pendidik agar peserta didik bisa berbahasa lebih santun sesuai dengan situasi dan lawan tutur yang diajak berbicara.
Kesantunan seseorang akan dihargai apabila ia dapat menempatkan bahasa lisan dan bahasa tubuhnya dengan baik. Berbicara mengenai bahasa, bahasa dibagi menjadi dua bahasa tulis dan bahasa lisan. Bahasa tulis meliputi majalah, koran. Sedangkan bahasa lisan meliputi radio dan televisi.

Televisi merupakan salah satu media massa yang populer di kalangan masyarakat. Hampir sebagian besar penduduk dunia memanfaatkan televisi sebagai sarana memperoleh hiburan, informasi, maupun edukasi. Berbagai berita tanah air dapat disaksikan di televisi. Ada banyak program di televisi seperti program berita, musik, game show, talk show, dan lain-lain.

Salah satu acara talk show yang dapat dijumpai di televisi swasta adalah $Q \& A$ yang dipandu oleh Andini Effendi. Talk show $Q \& A$ di tayangkan setiap hari Rabu pukul 19.30 WIB di Metro TV. Talk show ini menghadirkan beberapa panelis dari berbagai kalangan seperti pakar hukum pidana, pakar komunikasi politik, komentator bola, komika, psikolog, budayawan, presenter, penulis dan anggota DPR. Sekaligus menghadirkan narasumber terkait topik yang sedang dibahas. Masyarakat diajak mengulas berbagai topik untuk mendapatkan jawaban dari topik tersebut.

Talk show $Q \& A$ berbeda dengan talk show lainnya hal ini dikarenakan dalam talk show tersebut menghadirkan panelis dari berbagai kalangan untuk bertanya kepada narasumber terkait topik yang di bahas, sedangkan peran pembawa acara adalah penengah panelis dan narasumber. Panelis memiliki jabatan yang berbeda-beda akan menunjukan 
kesantunan berbahasa yang berbeda. Jika dalam talk show lainnya hanya pembawa acara yang memberi pertanyaan untuk narasumbernya lain hal dengan talk show Q\&A yang menghadirkan panelis untuk menanyakan terkait topik yang sedang dibahas. Talk Show $Q \& A$ bisa menjadi salah satu media pembelajaran bagi peserta didik

Berdasarkan uraian tersebut maka penulis tertarik meneliti strategi kesantunan berbahasa dalam talk show $Q \& A$ dan relevansinya terhadap pembelajaran bahasa Indonesia di SMP.

\section{METODE PENELITIAN}

Metode yang digunakan pada penelitian ini adalah metode deskriptif. Pendekatan yang digunakan dalam penelitian ini adalah pendekatan kualitatif. Sebuah pendekatan penelitian yang bertujuan untuk memberikan atau menjabarkan suatu keadaan atau fenomena yang terjadi saat ini dengan menggunakan prosedur ilmiah untuk menjawab masalah secara aktual (Sugiyono, 2015:207). Data yang dijadikan bahan penelitian adalah teks yang berupa kata atau kalimat berupa tuturan yang menunjukkan strategi kesantunan berbahasa pada talkshow $Q \& A$ di Metro TV. Pengumpulan data menggunakan teknik dokumentasi. Adapun langkah-langkah pengumpulan data, yaitu Mengunduh video talkshow $Q \& A$ yang ditayangkan Metro TV di youtube pada 20 Juni 2018, Mentranskrip video talkshow $Q \& A$ di Metro TV ke dalam tulisan, Mengidentifikasi kalimat kesantunan Brown dan Levinson pada talkshow $Q \& A$ di Metro TV yang termasuk dalam tuturan, Menginterpretasikan data,
Menyimpulkan hasil pengumpulan data.

\section{HASIL DAN PEMBAHASAN}

1. Strategi kesantunan berbahasa Brown dan levinson dalam talk show Q\&A

Strategi kesantunan berbahasa Brown dan Levinson yang digunakan dalam talk show Q\&A lebih banyak ditemukan pada strategi kesantunan positif dan negatif. Berikut akan diuraikan strategi kesantunan Brown dan Levinson.

\section{a. Bald on Record Strategy (tanpa strategi)}

Penutur tidak melakukan usaha apapun untuk meminimalisir ancaman muka lawan tutur atau untuk mengurangi tindakan yang mengancam muka. Strategi ini mengakibatkan mitra tutur merasa terkejut dan tidak nyaman. Berdasarkan data yang diperoleh, ditemukan strategi kesantunan bald on record strategy hal itu terlihat pada tuturan sebagai berikut.

$\begin{array}{lr}\text { “..............boleh dong } \\ \text { dibuka ke kita } & \text { semuanya } \\ \text { semata-mata } & \text { untuk } \\ \text { menggaet } & \text { popularitas, } \\ \text { kepentingan } & \text { industry } \\ \text { belaka atau bagaimana } & \text { baimana } \\ \left.\text { sih, nik?" ( } \mathrm{T}_{1} \mathrm{~S}_{1} \mathrm{P}_{6} \mathrm{NR}_{13}\right)\end{array}$

Tuturan tersebut disampaikan oleh Nuning Rodiyah komisioner. Dalam tuturan di atas petutur tidak meminimalisir ancaman bagi muka lawan tutur sehingga petutur dibuat kaget dan merasa tidak nyaman karena nuning rodiyah memaksa nikita untuk menceritakan apakah kontroversi yang terjadi hanya untuk popularitas saja atau memang benar terjadi. 
"Loh artinya UndangUndang mengatakan kalau ulama ya ulama aja gak usah masuk pemerintah gitu loh" $\left(\mathrm{T}_{3} \mathrm{~S}_{3} \mathrm{P}_{8} \mathrm{ST}_{5}\right)$

Data $\mathrm{T}_{3} \mathrm{~S}_{3} \mathrm{P}_{8} \mathrm{ST}_{5}$ termasuk dalam strategi bald on record karena Sudjiwo Tedjo tidak meminimalisir ancaman bagi muka lawan tutur sehingga tuturan "ulama ya ulama aja gak usah masuk pemerintah" membuat lawan tutur merasa tidak nyaman karena merasa bahwa Pak Ma'ruf sebagai ulama memang diajak Pak Jokowi untuk menjadi Calon Wakil Presiden.

\section{b. Possitive Pollitenes Strategy (Strategi kesantunan positif)}

Berdasarkan data yang diperoleh, ditemukan strategi kesantunan positif yaitu, memberi perhatian kepada lawan tutur, membesar-besarkan perhatian, persetujuan, dan simpati, mengintensifkan perhatian lawan tutur dengan pendramatisan fakta, mengintensifkan menggunakan penanda identitas kelompok, meminta persetujuan dengan topik yang umum atau mengulang sebagian atau seluruh, menghindari ketidaksetujuan dengan pura-pura setuju, menggunakan lelucon, menyatakan paham akan keinginan penutur, memberi tawaran atau janji, menunjukan keoptimisan, melibatkan penutur dalam aktivitas, memberikan pertanyaan meminta persetujuan, memberikan hadiah. Adapun pemaparan masing-masing strategi sebagai berikut.

\section{1) Memberi perhatian kepada lawan tutur}

Penggunaan strategi memberi perhatian kepada lawan tutur dalam talk show $Q \& A$ dapat dilihat pada data berikut.

"Saya rasa mbk niki yang dulu maupun mbk niki yang sekarang tetap seoarng wanita yang luar biasa bagi saya. saya sangat mengagumi mbk niki ketika di masa-masa kontroversi gitu ya. Bagi saya perempuan yang cukup kuat secara mental dan emosional bisa keluar dari standar moralitas orang lain" $\left(\mathrm{T}_{1} \mathrm{~S}_{2} \mathrm{P}_{8} \mathrm{NZ}_{1}\right)$

Pada kode $\quad \mathrm{T}_{1} \mathrm{~S}_{2} \mathrm{P}_{8} \mathrm{NZ}_{1}$ disampaikan oleh Nayla Rizki Zaskia. Tuturan bertujuan untuk memberi perhatian kepada lawan tutur. Hal ini dapat dilihat pada tuturan Nayla " $m b k$ Niki yang sekarang tetap seorang wanita yang luar biasa bagi saya. Saya sangat mengagumi mbk Niki”. Nayla memberikan perhatian khusus kepada Nikita dengan cara memuji Nikita.

2) Membesar-besarkan perhatian, persetujuan, dan simpati

Penggunaan strategi membesarbesarkan perhatian, persetujuan, dan simpati dalam talk show $Q \& A$ dapat dilihat pada data berikut.

"Because I love you niki. Kamu bisa jadi orang baik. Apalagi tadi kmu bilang bekerja untuk dua orang anak kamu. Itu ya allah tugas ibu yang sangat suci. Yang sangat barokah yang sangat diberikan rahmat oleh Tuhan" $\left(\mathrm{T}_{1} \mathrm{~S}_{2} \mathrm{P}_{10} \mathrm{DM}_{2}\right)$

Pada data $\mathrm{T}_{1} \mathrm{~S}_{2} \mathrm{P}_{10} \mathrm{DM}_{2}$ dengan tuturan "Because I love you niki. Kamu bisa jadi orang baik" Dewi Motik berharap dengan perubahan Nikita yang sekarang menggunakan 
hijab bisa membuat Nikita lebih baik dari sebelumnya. Tuturan tersebut dapat dilihat dibawah ini.

\section{3) Mengintensifkan perhatian lawan tutur dengan pendramatisan fakta}

Penggunaan strategi mengintensifkan perhatian lawan tutur dengan pendramatisan fakta dalam talk show $Q \& A$ dapat dilihat pada data berikut.

"Kalau ini penting sekali ya tidak ada saling membohongi atau mengkhianati untuk satu kepentingan yang negatif sifatnya tidak tapi, ini bagian dari salah satu pola komunikasi untuk satu tugas yang sangat penting. Di seluruh negara di dunia ini dalam rangka memilih itu pasti calon tidak satu. Pasti ada beberapa calon" $\left(\mathrm{T}_{3} \mathrm{~S}_{1} \mathrm{P}_{2} \mathrm{JP}_{5}\right)$ Pada data $\mathrm{T}_{3} \mathrm{~S}_{1} \mathrm{P}_{2} \mathrm{JP}_{5}$ juga termasuk mengintensifkan perhatian lawan tutur dengan pendramatisan fakta. Hal itu dapat dibuktikan pada tuturan Johnny G. Plate "tidak ada saling membohongi atau mengkhianati untuk satu kepentingan yang negatif" Johnny berusaha meyakinkan lawan tutur dengan pendramatisan tuturan tersebut agar lawan tutur percaya bahwa memang Johnny tidak berbohong dan mengkhianati.

\section{4) Menggunakan penanda identitas kelompok}

Penggunaan mengintensifkan strategi penanda identitas kelompok dalam talk show $Q \& A$ dapat dilihat pada data berikut.

"Saya sih sepakat sama bang joni tadi bilang ya ada drama" $\left(\mathrm{T}_{2} \mathrm{~S}_{1} \mathrm{P}_{5} \mathrm{PS}_{1}\right)$
Dalam tuturan tersebut terlihat bahwa penutur menggunakan sapaan bang. Hal ini dikarenakan untuk membuat kedekatan hubungan penutur dengan mitra tutur. Kata bang yang digunakan oleh penutur untuk berlangsungnya komunikasi secara lancar.

"Mbah Tedjo silahkan"
$\left(\mathrm{T}_{3} \mathrm{~S}_{3} \mathrm{P}_{1} \mathrm{AE}_{5}\right)$

Dalam tuturan tersebut terlihat bahwa penutur menggunakan sapaan mbah. Hal ini dikarenakan untuk membuat kedekatan hubungan penutur dengan mitra tutur. penutur menggunakan sapaan mbah karena Sudjiwo dianggap lebih tua dari Andini dan supaya lebih akrab digunakanlah sapaan tersebut.

5) Meminta persetujuan dengan topik yang umum atau mengulang sebagian atau seluruh

Penggunaan strategi meminta persetujuan dengan topik yang umum atau mengulang sebagian atau seluruh dalam talk show $Q \& A$ dapat dilihat pada data berikut.

Nayla menyepakati tuturan Andini untuk meluruskan pertanyaannya yang ditanyakan pada Nikita dengan menggunkan kata iya agar nikita juga lebih paham dan bisa menjawab pertanyaan dari Nayla.

$\mathrm{AE}_{51}$ : "Jadi, sekarang fokusnya lebih ke bisnis?"

$\mathrm{KS}_{9} \quad$ : "Iya, jadi aku lebih fokusnya ke bisnis" $\left(\mathrm{T}_{1} \mathrm{~S}_{4} \mathrm{P}_{3} \mathrm{KS}_{9}\right)$

$\begin{array}{lr}\text { Kumalasari } & \text { menyepakati } \\ \text { jawaban Andini } & \text { dengan } \\ \text { menggunakan kata iya } & \text { bahwa dirinya } \\ \text { sekarang jarang muncul di }\end{array}$


televiskarena lebih fokus ke bisnisnya.

\section{6) Menghindari ketidaksetujuan} dengan pura-pura setuju

Penggunaan strategi menghindari ketidaksetujuan dengan pura-pura setuju

dalam talk show $Q \& A$ dapat dilihat pada data berikut.

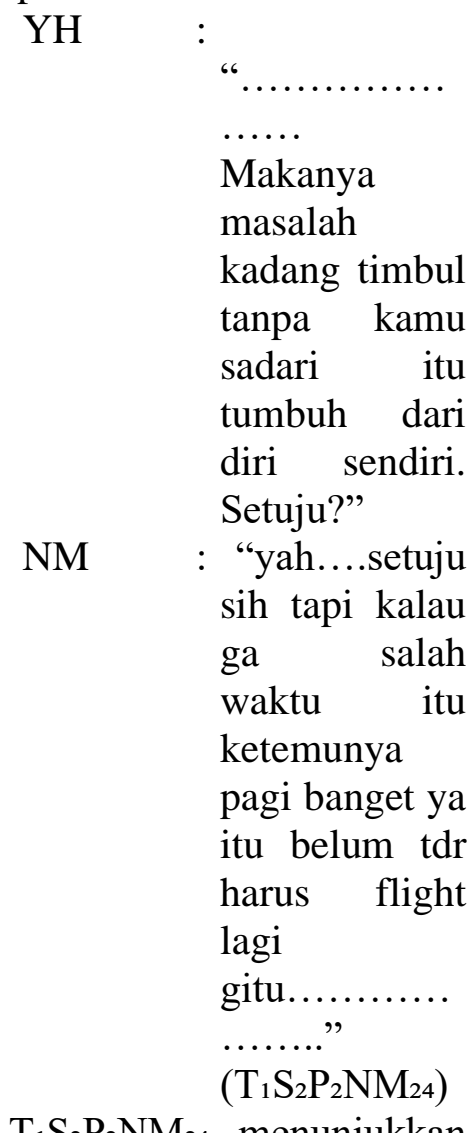

Data $\mathrm{T}_{1} \mathrm{~S}_{2} \mathrm{P}_{2} \mathrm{NM}_{24}$ menunjukkan bahwa Nikita berpura-pura setuju dengan menggukan kata yah setuju kemudian diberikan penjelas bahwa nikita waktu bertemu Yulia berada di Bandara dan harus menuju kota-kota lainnya untuk urusan pekerjaan. Hal itu menunjukan bahwa sebenarnya nikita tidak setuju dikatakan oleh Yulia bahwa masalah datang dari dirinya sendiri sehingga menyebabkan Niita menjadi artis kontroversi.

\section{7) Menggunakan lelucon}

Penggunaan strategi menggunakan lelucon dalam talk show $Q \& A$ dapat dilihat pada data berikut.

"Mama tuh mau deh kalau masak di dapur itu pakai baju renang atau ngulek cabe pakai baju renang. Ya biar kehlihatan seksi gitu nik. Tapi kalau mama berenang, mama pakai kebaya" $\left(\mathrm{T}_{1} \mathrm{~S}_{4} \mathrm{P}_{11} \mathrm{MA}_{6}\right)$

Mama Apip bergurau atau membuat lelucon dengan mengucapkan "ngulek cabe pakai baju renang" dan "kalau mama berenang, mama pakai kebaya” Hal ini membuat satu studio menjadi tertawa.

8) Menyatakan paham akan keinginan penutur

Penggunaan strategi menyatakan paham akan keinginan penutur dalam talk show $Q \& A$ dapat dilihat pada data berikut.

"Sekarang gini sebagai guru grooming. Aku percaya kamu tidak mencari sensasi. Tetapi dalam hidup manusia itu ada yang datang ada yang kita ciptakan sendiri. Mungkin kamu tidak sadar problem itu kamu ciptakan sendiri dengan behavior tata acara kamu" $\left(\mathrm{T}_{1} \mathrm{~S}_{2} \mathrm{P}_{5} \mathrm{YH}_{1}\right)$

$\mathrm{T}_{1} \mathrm{~S}_{2} \mathrm{P}_{5} \mathrm{YH}_{1} \quad$ Tuturan ini diujarkan oleh Yulia Hartanto kepada Nikita bahwa dia memahami keinginan Nikita sebenernya nikita tidak ingin mencari sensasi. Hal itu dapat dilihat pada tuturan " $A k u$ percaya kamu tidak mencari sensasi" tuturan tersebut termasuk pengkategorian 
menyatakan paham akan keinginan penutur.

\section{9) Memberi tawaran atau janji}

Penggunaan strategi memberi tawaran atau janji dalam talk show $Q \& A$ dapat dilihat pada data berikut.

"Oke, kita harus kembali break lagi. Tapi masih ada narasumber satu lagi ini yang juga kita katanya lambe julid. Namanya Kumalasari. Setelah jeda berikut ini" $\left(\mathrm{T}_{1} \mathrm{~S}_{3} \mathrm{P}_{1} \mathrm{AE}_{29}\right)$

Andini Effendi juga menggunakan strategi memberi tawaran atau janji. "Tapi masih ada narasumber satu lagi ini yang juga kita katanya lambe julid" tuturan tersebut terlihat bahwa Andini memberikan janji kepada penonton untuk menghadirkan narasumber selain Nikita setelah jeda iklan. Hal itu dapat dilihat pada Data $\mathrm{T}_{1} \mathrm{~S}_{3} \mathrm{P}_{1} \mathrm{AE}_{29}$.

\section{0) Menunjukan keoptimisan}

Penggunaan strategi menunjukan keoptimisan dalam talk show $Q \& A$ dapat dilihat pada data berikut.

$\mathrm{AE}_{2} \quad$ : "yang kedua silahkan "gak tahu kenapa aku kok mikirnya deseu gak bakalan lama berkerudungnya hehehe maafkan. Banyak yang ragu tuh katanya akan stay berhijab"

NM : "Alhamdulillah justru itu makin menguatkan niki untuk gak pernah lepas" $\left(\mathrm{T}_{1} \mathrm{~S}_{3} \mathrm{P}_{2} \mathrm{NM}_{22}\right)$

Tuturan "Alhamdulillah justru itu makin menguatkan niki untuk gak pernah lepas" termasuk pengkategorian menunjukkan keoptimisan. Nikita sangat optimis bahwa dirinya tidak akan melepas jilbabnya walaupun banyak sekali netizen yang menganggap bahwa Nikita tidak mungkin bertahan lama mengenakan jilbab. Tuturan tersebut dapat dilihat pada data $\mathrm{T}_{1} \mathrm{~S}_{3} \mathrm{P}_{2} \mathrm{NM}_{22}$.

11) Melibatkan penutur dalam aktivitas

Penggunaan strategi melibatkan penutur dalam aktivitas dalam talk show $Q \& A$ dapat dilihat pada data berikut.

Kata yang digunakan untuk melibatkan penutur dalam aktivitas adalah kata"kita". Hal itu dapat dilihat pada kode $\mathrm{T}_{1} \mathrm{~S}_{4} \mathrm{P}_{1} \mathrm{AE}_{30}$

"Silahkan mbk kumala bergabung bersama kita. Terima kasih sudah bergabung di acara Q\&A silahkan duduk di kursi panas kita, kursi narasumber. Kita kasih lihat cuplikannya siapa kumalasari" $\left(\mathrm{T}_{1} \mathrm{~S}_{4} \mathrm{P}_{1} \mathrm{AE}_{30}\right)$.

\section{2) Memberikan pertanyaan meminta persetujuan}

Penggunaan strategi memberikan pertanyaan meminta persetujuan dalam talk show $Q \& A$ dapat dilihat pada data berikut.

"Apakah memang sifatnya pada saat itu yang lebih melawan jadinya lebih ngedatengin banyak masalah atau memang masaalhnya aja yang ngedatengin sendiri kalau menurut niki?" $\left(\mathrm{T}_{1} \mathrm{~S}_{1} \mathrm{P}_{5} \mathrm{YH}_{1}\right)$

Tuturan Yuliana Hartanto termasuk dalam kategori memberikan pertanyaan kepada Nikita. Hal itu dapat dilihat pada data $\mathrm{T}_{1} \mathrm{~S}_{1} \mathrm{P}_{5} \mathrm{YH}_{1}$ yang menunjukan tuturan "Apakah memang sifatnya pada saat itu yang lebih melawan........". Hal ini 
dilakukan untuk memperlancar komunikasi antara penutur dan lawan tutur.

\section{3) Memberikan Hadiah}

Penggunaan strategi memberikan hadiah dalam talk show $Q \& A$ dapat dilihat pada data berikut.Hadiah yang diberikan tidak harus berupa benda, Hadiah juga bisa berupa tepuk tangan terhadap Mitra tutur.

"oke sekali lagi tepuk tangan untuk mbk niki ya. luar biasa sekali.........." $\left(\mathrm{T}_{1} \mathrm{~S}_{2} \mathrm{P}_{8} \mathrm{NZ}_{1}\right)$

Tuturan Nayla pada data $\mathrm{T}_{1} \mathrm{~S}_{2} \mathrm{P}_{8} \mathrm{NZ}_{1}$ yang menyatakan member hadiah kepada nikita adalah Nayla memberikan tepuk tangan dan meminta seluruh yang ada distudio untuk memberikan tepuk tangan kepada Nikita. Bentuk hadiah yang diberikan Nayla berupa tepuk tangan. Selain Nayla, Andini Efendi juga meminta kepada penonton untuk memberikan apresiasi kepada lawak junior dalam bentuk tepuk tangan. Hal itu dapat dilihat pada data $\mathrm{T}_{4} \mathrm{~S}_{1} \mathrm{P}_{1} \mathrm{AE}_{8}$

\section{c. Negative Politeness Strategy (Strategi Kesantunan Negatif)}

Berdasarkan data yang diperoleh, peneliti menemukan strategi kesantunan negatif yang meliputi Sedangkan strategi kesantunan negatif ditemukan bersikap pesimis, meminimalkan paksaan, dan meminta maaf.. Adapaun pemaparan sebagai berikut.

\section{1) Bersikap pesimis}

Berdasarkan data yang diperoleh, ditemukan strategi kesantunan yang termasuk dalam kategori bersikap pesimis. Hal ini dapat dilihat pada tuturan berikut ini. "saya bisa bicara tentang
komisi saya sendiri yaitu
komisi 8 tentunya saya
sebagai aktivis terbiasa
dengan being produktif gitu ya
istilahnya cukup frustasi
sampai kalau boleh jujur saya
sempat memikirkan saya mau
mundur saja tetapi, saya balik
lagi harus mengingat
masyarakat dapil saya"
$\left(\mathrm{T}_{2} \mathrm{~S}_{3} \mathrm{P}_{3} \mathrm{RW}_{15}\right)$

Data $\mathrm{T}_{2} \mathrm{~S}_{3} \mathrm{P}_{3} \mathrm{RW}_{15}$ termasuk dalam kategori bersikap pesimis. Rahayu Saraswati merasa pesimis sebagai anggota DPR karena banyak tugas yang harus diselesaikan bahkan Rahayu berniat mengundurkan diri sebagai anggota DPR. Hal itu terlihat pada tuturan tuturan Rahayu "cukup frustasi sampai kalau boleh jujur saya sempat memikirkan saya mau mundur saja"

\section{2) Meminimalkan paksaan}

Penggunaan strategi meminimalkan paksaan dalam talk show $Q \& A$ dapat dilihat pada data berikut.

"Saya mau lanjut dengan data yang tadi boleh ya? nah ini data ini kita katakana minus lah ya semuanya. Pertanyaannya dengan bung maman itu tadi apakah anda merasa anggota DPR anda sukses? Kalau iya, apakah ukuran anda sukses dengan begini? Kalau tidak, masihkan secara moral anda akan melanjutkan untuk dipilih pada tahun 2019 yang akan datang?" $\left(\mathrm{T}_{2} \mathrm{~S}_{3} \mathrm{P}_{10} \mathrm{RR}_{5}\right)$ 
Tuturan Ray Rangkuti pada data $\mathrm{T}_{2} \mathrm{~S}_{3} \mathrm{P}_{10} \mathrm{RR}_{5}$ termasuk dalam meminimalkan paksaan. Ray sebenarnya memaksa ingin melanjutkan pertanyaannya karena pertanyaannya belum sepenuhnya terjawab oleh narasumber sehingga ray ingin melanjutkan lagi pertanyaannya dengan meminta izin terlebih baru memberi pertanyaan meskipun Andini belum mengizinkan. Hal itu dapat dilihat pada tuturan "Saya mau lanjut dengan data yang tadi boleh ya?".

\section{3) Meminta maaf}

Penggunaan strategi meminta maaf dalam talk show $Q \& A$ dapat dilihat pada data berikut.

"Maaf...maaf.....saya...saya

....saya menjawab. Kalau ini penting sekali ya tidak ada saling membohongi atau mengkhianati untuk satu kepentingan yang negative sifatnya tidak tapi, ini bagian dari salah satu pola komunikasi untuk satu tugas yang sangat penting. di seluruh negara di dunia ini dalam rangka memilih itu pasti calon tidak satu. Pasti ada beberapa calon." $\left(\mathrm{T}_{3} \mathrm{~S}_{1} \mathrm{P}_{2} \mathrm{JP}_{5}\right)$

Pada tuturan tersebut meminta "maaf" telah memotong jawaban petutur lain karena ia merasa jawaban yang diberikan temannya tadi tidak membuat mitra tutur paham dengan makasud yang dipaparkan untuk itu penuturlah yang ingin menjawab.

d. Off Record Pollitenes Strategy (Strategi tidak langsung atau tersamar)

Strategi ini digunakan jika penutur ingin melakukan tindakan mengancam muka namun tidak ingin bertanggung jawab atas tindakan tersebut. Berdasarkan data yang diperoleh, ditemukan strategi kesantunan off record strategy hal itu terlihat pada tuturan sebagai berikut. "Jadi, kenapa parlemen kami perlu adanya Presidential Threshold?

Karena kita gak mau bikin rakyat bingung. Jujur saja semua calon ini baik, why not the best? Kenapa tidak yang terbaik? Saya rasa Pak Joko Widodo. Kenapa? Karena beliau sudah hampir merampungkan periode yang pertama. Tadi pertanyaan Andini baik sekali. Udah jelas enggak ini Pak Prabowo? Karena saya lihat kawankawan koalisinya ini agak mencla-mencle loh hati-hati. Kosong delapan ini orang baik, dia juga aset. Ada gak pemikiran Saras bilang sama om nya "udalah jadi Wapresnya Pak Jokowi aja?" $\left(\mathrm{T}_{2} \mathrm{~S}_{4} \mathrm{P}_{9} \mathrm{RS}_{4}\right)$

Pada tuturan ini menyatakan tidak langsung. Hal ini diungkapkan pada tuturan Jujur saja semua calon ini baik, why not the best? Kenapa tidak yang terbaik? Saya rasa Pak Joko Widodo. Maksud dari tuturan Ruhut adalah ingin mngajukan Pak Jokowi sebagai capres daripada Indonesia harus di bawah pimpinan Pak Prabowo.

2. Relevansi strategi kesantunan berbahasa terhadap pembelajaran Bahasa Indonesia tingkat SMP Kesantunan berbahasa bukan untuk politisi dan pejabat tinggi, namun yang tidak kalah pentingnya 
yakni bagi pelajar dalam bersikap dan bertutur harus memperhatikan etika berbahasa. Kesantunan berbahasa dalam talk show Q\&A di Metro TV memiliki kaitan di dalam usaha untuk proses belajar sikap santun peserta didik. Pada relevansi atau keterkaitan strategi kesantunan berbahasa pada talk show Q\&A terhadap pembelajaran bahasa Indonesia tingkat SMP sesuai dengan KD 3.94.10 yaitu, mengidentifikasi informasi teks diskusi berupa pendapat pro dan kontra dalam teks diskusi berkaitan dengan permasalahan actual yang dibaca dan didengar, sampai pada menyajikan gagasan/pendapat, argument yang mendukung dan yang kontra serta solusi atas permasalahan actual dalam teks diskusi dengan memperhatikan struktur dan aspek kebahasaan, dan aspek lisan (intonasi, gesture, pelafalan). Berikut kutipan yang sesuai dengan KD SMP.

AE : "Jadi kalau ada yang minta bantuan gak bisa bantu gak pernah dijanjiin gitu?"

$\mathrm{CH}_{4} \quad$ : "Iya"

$\mathrm{RR}_{2}$ : "maksud saya gini loh, kalau saya pribadi sih emang gak melihat janji itu dalam bentuk materi kayak gitu, tapi apa yang anda kerjakan sebagai DPR dalam peningkatan kualitas demokrasi Indonesia. Nah, itu yang saya bayangkan tapi, kalau pikiran itu pun anda gak ada lalu andaanda gak rajin datang ke DPR ya dudukduduk saja itu namanya. Jadi, ketika

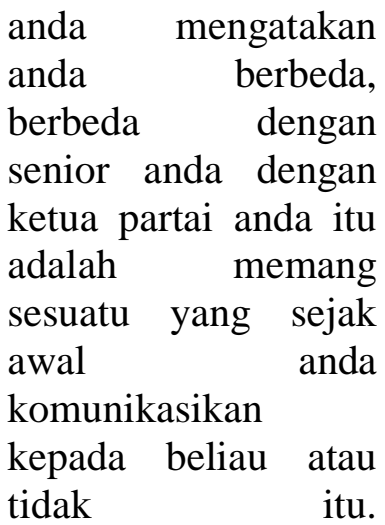

$\mathrm{AS}_{6}$ : “jadi gini kalau bicara tentang yang abang sampaikan semakin masyarakat ke bawah tentang teknis, tentang situasi DPR, nanti saya begini. Dia semakin gak suka sama kita. Semakin gak dipilih sama dia yang ada dimasyarakat adalah elu peduli gak sih sama masyarakat? Kepedulian elu bukan tentang teknis DPR"

Tuturan di atas apabila dikaitkan pada KD SMP termasuk ke dalam KD 3.9 yaitu, mengidentifikasi informasi teks diskusi berupa pendapat pro dan kontra dalam teks diskusi berkaitan dengan permasalahan aktual yang dibaca dan didengar. jadi peserta didik bisa mengidentifikasi pendapat pro dan kontra dari tuturan tersebut.

\section{SIMPULAN}

Strategi kesantunan brown dan levinson yang pertama yaitu tanpa strategi. Dalam talk show Q\&A menggunakan tiga kutipan yang termasuk dalam bald on record strategy (tanpa strategi). Strategi 
kesantunan yang paling dominan ditemukan dalam tuturan talk show $Q \& A$ yaitu 13 strategi positif karena dalam talk show Q\&A panelis dan narasumber lebih mengacu pada citra diri untuk mempertahankan keyakinannya untuk diakui dan 3 strategi negative karena narasumber dan panelis ingin dihargai dan bebas melakukan keinginannya dalam bertutur maupun bertindak. Sedangkan strategi kesantunan brown dan levinson yang keempat yaitu strategi tidak langsung atau tersamar. Sama halnya dengan tanpa strategi, strategi ini jarang ditemukan dalam transkip talk show. Hanya terdapat satu kutipan yang menunjukkan bahwa strategi tidak langsung. Dalam strategi ini penutur membiarkan mitra tutur menginterpretasikan sendiri suatu tindakan.

Relevansi atau keterkaitan strategi kesantunan berbahasa pada talk show Q\&A bisa dijadikan sebagai salah satu media pembelajaran agar peserta didik lebih memahami mengenai materi diskusi sesuai KD 3.9-4.10 yaitu, mengidentifikasi informasi teks diskusi berupa pendapat pro dan kontra dalam teks diskusi berkaitan dengan permasalahan aktual yang dibaca dan didengar, sampai pada menyajikan gagasan/pendapat, argument yang mendukung dan yang kontra serta solusi atas permasalahan aktual dalam teks diskusi dengan memperhatikan struktur dan aspek kebahasaan, dan aspek lisan.

\section{DAFTAR PUSTAKA}

Chaer, Abdul. 2009. Psikolinguistik. Jakarta: Rineka Cipta.

Chaer, Abdul. 2010. Kesantunan Berbahasa. Jakarta: Rineka Cipta.
Brown, P. dan Levinson, S.C. 1987. Politeness Some Universals in Language Usage. New York: Cambridge University Press.

Halid, Elan. 2017. Kesantunan Berbahasa dalam kegiatan diskusi Mahasiswa Angkatan 2016 Program Studi DIII Keperawatan Solok Poltekkes Kemenkes Padang. Universitas Mahaputra Muhammad Yamin. (http://www.journal.uad.ac.id/in dex.php/BAHASTRA/article/vi ew/5957)

diunduh hari Sabtu 4 Agustus 2018 pukul 01.20 WIB.

Gunarwam, Asim. 2007. Pragmatik: Teori dan Kajian Nusantara. Jakarta: Universitas Atmajaya.

Muslim, Bukhori. 2017. Penyimpangan teori Brown dan Levinson dalam Tindak Tutur Peserta Talkshow Indonesia Lawyers Club di TV One dan Relevansinya terhadap Pembelajaran Bahasa Indonesia di SMA. Universitas Mataram.

(http://eprints.unram.ac.id/6736/ ) diunduh hari Sabtu 4 Agustus 2018 pukul 01.00 WIB.

Nadar, Fransicus Xaverious. 20013. Pragmatik dan Penelitian Pragmatik. Yogyakarta: Graha Ilmu.

Pramujiono, Agung. 2015. Representasi Kesantunan Positif-Negatif dalam Wacana Dialog di Televisi. Universitas PGRI Adi Buana Surabaya.

(http://www.journal.uad.ac.id/in dex.php/BAHASTRA/article/vi ew/2717)

diunduh hari Sabtu 4 Agustus 2018 pukul 00.35 WIB. 
Rahardi, Kunjana. 2009 . Sosiopragmatik. Jakarta: Penerbit Erlangga.

Sugiyono. 2015. Metode Penelitian Kualitatif Kuantitatif dan $R \& D$. Bandung: CV.Alfabet.

Verhaar. 2012. Asas-Asas Linguistik Umum. Yogyakarta: Gadjah Mada University Press.
Widodo dan I wayan Ardi. 2016. Prinsip Percakapan (Pengantar Pemahaman Santun Berbahasa). Yogyakarta: Textium.

Yule, George. 2006. Pragmatik (terjemahan). Yogyakarta: Pustaka Pelajar. 